\title{
Aspectos éticos do uso de produtos fluorados no Brasil: uma visão dos formuladores de políticas públicas de saúde
}

\author{
Ethical aspects of the use of fluoride products \\ in Brazil: a view of public health policy formulators
}

Pola Alessandra Kalamatianos 1

Paulo Capel Narvai 1

${ }^{1}$ Faculdade de Saúde Pública da USP.

Av. Dr. Arnaldo 715

Cerqueira César, 01246-904,

São Paulo SP.

plkal@directnet.com.br
Abstract Fluoride has been used to prevent dental caries. It is used in supply water and toothpastes. One undesirable effect has been found: mild dental fluorosis. Such stains have aroused concern among specialists. This paper examines, in the literature, ethical aspects resulting from the use of fluoride in public health associated with the "caries prevention versus mild fluorosis occurrence" contradiction and investigates the occurrence of any ethical dilemma among the professionals involved in decision on the use of such products. Databases were assessed to identify papers through terms such as ética, bioética, ethics and fluor. The material contributed to the drawing up of a questionnaire answered by researchers and health authorities. The data provided by the interviews underwent content analysis. The ethics dilemma may be stated as: "The use of fluoride products to prevent dental caries has in public health the inconvenience of producing mild dental fluorosis in the population, however, the nonuse of fluoride has the inconvenience of not preventing the appearance of a disease (caries) that can be prevented if such product is used." The dilemma has shown to be solved, by admitting that the use of such products would be fair and that its benefit would exceed its damages. Nevertheless, some of the respondents admitted a violation of the principle of autonomy.

Key words Ethics, Public health, Fluor, Water fluoridation
Resumo O flúor tem sido empregado para prevenir cárie dentária, principalmente em águas de abastecimento e dentifrícios. Um efeito indesejável, a fluorose dentária leve, tem suscitado preocupações entre especialistas. Neste trabalho identificam-se, na literatura, aspectos éticos decorrentes do emprego de flúor em saúde pública relacionados à contradição "prevenção da cárie versus ocorrência de fluorose leve" e investiga-se a ocorrência de dilemas éticos entre profissionais envolvidos em decisões sobre o uso desses produtos. Foram identificadas publicações em bases de dados empregando-se os termos de busca ética, bioética, "ethics" e derivações do radical "fluor". O material subsidiou a construção de um questionário aplicado a pesquisadores e autoridades sanitárias, e os dados gerados submetidos à análise de conteúdo. O dilema ético emergente da análise pode ser sintetizado: "Empregar produto com flúor para prevenir cárie dentária tem o inconveniente de produzir graus leves de fluorose dentária, mas não utilizá-lo em saúde pública tem o inconveniente de não impedir o aparecimento de uma doença (cárie) evitável com o seu uso." Tal dilema tem sido resolvido admitindo-se que haveria justiça no emprego do flúor e que seu benefício seria maior do que o malefício - sendo este mínimo. Alguns entrevistados reconheceram que há violação do princípio ético da autonomia.

Palavras-chave Ética, Saúde pública, Flúor, Fluoretação da água 


\section{Introdução}

Os dilemas morais decorrentes de intervenções de saúde pública vêm sendo objeto de preocupações entre os formuladores de políticas públicas e os tomadores de decisões nessa área. Esses dilemas impactam as áreas de bioética e de saúde pública, que, apesar de constituírem campos distintos, apresentam pontos de interseção, possibilitando uma abordagem mais abrangente dos conflitos éticos pertinentes à aplicação de tecnologias em saúde (Garrafa ${ }^{1}$, Schramm \& Kottow2).

As ações de saúde pública resultam de decisões políticas e se materializam em medidas que aparecem como respostas às necessidades sanitárias coletivas. Com a finalidade de proteger a todos numa determinada sociedade, essas medidas tornam-se obrigatórias e sua execução legitima o exercício do poder de disciplina e de autoridade. Argumenta-se que a legitimidade das ações sanitárias e as restrições à autonomia individual se constituiriam em características dos atos protetores e, dessa forma, a justiça sanitária prevaleceria sobre a autonomia individual (Schramm \& Kottow2).

Enquanto o princípio da proteção está associado às evidências sobre a eficácia e a necessidade de certas ações de alcance coletivo em saúde pública e ambiental, o princípio da prudência ou precaução associa-se aos danos e riscos potenciais oriundos dessas ações.

Formuladores de políticas públicas e tomadores de decisões em saúde se vêem, freqüentemente, em situações críticas, dilemáticas, em que se verificam conflitos entre os princípios de proteção e de precaução.

$\mathrm{Na}$ área da saúde, uma situação dilemática ocorre "quando duas abordagens são possíveis e defensáveis tecnicamente, existindo dúvidas quanto à adequação moral de cada escolha" $\left(\right.$ Goldim $\left.^{3}\right)$. Ao se analisar eticamente as decisões no campo da saúde, observa-se que a maior parte dos critérios adotados pelos tomadores de decisão é consoante com o princípio de utilidade social, segundo o qual uma decisão deve ser adotada de modo a "obter o maior bem-estar para o maior número possível de pessoas". Entretanto, não é essa a tendência observada entre os profissionais de saúde e a população (Fortes 4 ).

Tais conflitos e dilemas fazem com que, não obstante a saúde pública conte com um conjunto de possibilidades e ferramentas para suas intervenções - entre as quais as proporcionadas pela epidemiologia, pela saúde ambiental, pelas ciências sociais e humanas e por outros campos do conhecimento científico-tecnológico -, suas ações suscitem questionamentos éticos enquanto meios para se atingir determinadas metas, mesmo quando se reconhece que essas intervenções são amparadas por leis e, muitas vezes, bem-sucedidas na redução da morbimortalidade (Kass5).

Para vários autores, o emprego das tecnologias em saúde deveria avaliar os diferentes aspectos relativos à população-alvo, entre os quais as características socioculturais, os fatores econômicos e os aspectos biológicos que afetam os grupos sociais, além dos possíveis conflitos sociais e morais originados pelo seu uso. Problemas morais - como injustiças e restrições às liberdades individuais - podem surgir em nome do bem-estar e da segurança da coletividade; ou, até mesmo, quando os objetivos de determinada intervenção não são alcançados, devido a conflitos de interesses que impedem o acesso de amplas camadas da população às tecnologias (Frazão6, Schramm \& Escotesguy7, Fortes $\left.{ }^{8}\right)$. Por essa razão, é crucial, também, considerar o desafio da universalidade de acesso às tecnologias nas análises éticas das intervenções de saúde pública.

Uma análise ética das intervenções ou programas de saúde pública deve identificar, claramente, suas metas e benefícios expressos em termos de redução da morbidade e da mortalidade, e identificar os danos que possam decorrer dessas práticas, pois o equilíbrio entre danos e benefícios jamais será adequado sem uma justificativa de saúde pública (Kass5, Kalamatianos \& Narvai 9 ).

Produtos fluorados, especialmente águas de abastecimento público e dentifrícios, vêm sendo utilizados em todo o mundo para prevenir cárie dentária, como uma típica intervenção de saúde pública. Entretanto, um efeito indesejável tem sido detectado: a ocorrência de fluorose dentária leve, com um quadro clínico caracterizado pelo aparecimento de manchas brancas no esmalte dentário. Tal tipo de fluorose, mesmo que nem sempre percebido pelos portadores, tem suscitado preocupações entre os especialistas (Fejerskov et al. ${ }^{10}$, Murray ${ }^{11}$, McDonagh et al.12).

A fluoretação das águas, apesar de ter sido implementada por várias décadas em diversos países, inclusive no Brasil desde 1953, e configurar-se como uma medida efetiva, segura, equânime e barata contra a cárie dentária - ratificada por organizações científicas, médico- 
odontológicas e de saúde pública de todo o mundo (Horowitz ${ }^{13}$, Brasil14) -, vem sendo objeto de questionamentos éticos. Para Cohen \& Locker ${ }^{15}$, mesmo que fosse universalmente aceito que a fluoretação das águas é benéfica, e cientificamente inquestionável, ainda assim restaria uma dimensão moral quanto à conveniência do seu emprego. Tais questionamentos não ocorrem, contudo, com a mesma ênfase em relação à disponibilidade de dentifrícios e outros produtos contendo flúor, pois estes apresentam a alternativa de não serem consumidos quando isso não é desejado.

Adicionar flúor às águas de abastecimento para prevenir cárie, tendo em vista o princípio da proteção, ou não fazê-lo para auxiliar na prevenção da fluorose, considerando o princípio da precaução? Esta questão é discutida neste artigo, tendo como pano de fundo o contexto brasileiro no início do século 21, em que cerca de $40 \%$ da população tem acesso à água fluoretada, a ampla maioria dos dentifrícios são fluorados e a ocorrência de cárie aos 12 anos de idade revela magnitude aproximadamente 33\% menor entre os beneficiados por água fluoretada (Narvai16). E mais: segundo o Ministério da Saúde, os brasileiros apresentam, em média, 2,8 dentes permanentes atingidos pela doença na idade-índice de 12 anos (Brasil17). Esse valor corresponde a uma prevalência considerada "moderada" pela Organização Mundial da Saúde (World Health Organization 18 ), caracterizando a cárie dentária como um importante problema de saúde pública no Brasil, a exigir providências dos tomadores de decisão em saúde.

O objetivo deste trabalho é analisar possíveis dilemas éticos relacionados com o emprego de produtos fluorados em saúde pública, identificados tanto na literatura sobre o assunto quanto nas opiniões que têm sobre o tema os formuladores de políticas públicas de saúde e os tomadores de decisão nessa área.

Entre os objetivos específicos, procurou-se verificar como os profissionais envolvidos em decisões sobre o uso de produtos fluorados avaliam a contradição "prevenção da cárie versus ocorrência de fluorose leve", e se esses profissionais vivenciam algum dilema ético. Além disso, procurou-se identificar também o que pode amparar tais decisões, bem como os valores e princípios éticos que as balizam.

\section{Método}

Trata-se de pesquisa exploratória com abordagem qualitativa (Minayo19, Lefèvre et al.20), empregando-se a análise documental e a entrevista como técnicas para a obtenção de informações pertinentes ao objeto. As unidades da análise documental foram artigos e documentos oficiais; as da entrevista foram os discursos.

Para viabilizar a análise documental, foram realizadas buscas nas principais bases de dados que congregam periódicos nacionais e internacionais utilizados nas áreas de saúde pública, odontologia e bioética, a saber: Medline, Lilacs e BBO.

O levantamento abrangeu os artigos publicados entre os anos de 1966 a 2001, empregando-se termos de busca como "ética", "bioética", "ethics" e derivações do radical "fluor". Os dados foram coletados, sistematicamente, entre 2001 e 2002. Citações de interesse também foram rastreadas por vias não sistemáticas, a partir de referências secundárias, internet, leituras de rotina e consultas manuais na biblioteca da Faculdade de Saúde Pública da Universidade de São Paulo.

O material analisado foi composto de 39 artigos obtidos em periódicos científicos internacionais, indexados ou de reconhecida credibilidade para os profissionais de saúde pública e odontologia, três artigos disponibilizados em sítios da internet e um capítulo de livro. Na análise dos resultados, tomaram-se, como referencial, alguns princípios fundamentais da bioética, como a não-maleficência, a beneficência, a autonomia, a justiça, a proteção e a precaução. A partir da análise desse material, construiu-se um roteiro para as entrevistas realizadas com pesquisadores, autoridades sanitárias e lideranças médico-sanitárias, nas quais se buscou explorar aspectos relacionados com as contradições, os dilemas vivenciados, os valores e os princípios éticos que orientam suas decisões sobre o uso de produtos fluorados.

Como instrumento para a obtenção do discurso desses profissionais, utilizou-se a entrevista semi-estruturada. Um roteiro foi elaborado e previamente testado, ficando definidas as seguintes perguntas:

1) Sabe-se que a concentração de fluoretos nas águas de abastecimento está associada à queda da prevalência da cárie, e altamente associada à prevalência de fluorose dentária, podendo gerar um dilema para os que tomam decisões na área da Saúde Bucal Coletiva. O que você pensa disto? 
2) E o uso dos demais produtos fluorados em Saúde Pública? Comente.

3) No seu entender, quem deve participar das decisões sobre as questões relativas ao uso de produtos fluorados? As decisões devem se amparar em quê?

Através da utilização de uma amostra intencional de conveniência, não probabilística, foram entrevistados dez formuladores de políticas de saúde e tomadores de decisões, entre setembro e novembro de 2002, cujos depoimentos foram gravados, transcritos e analisados.

\section{Resultados}

\section{A literatura}

A análise da literatura revelou que, cronologicamente, os primeiros argumentos contra a fluoretação tinham relação com o princípio ético da autonomia, em que se alegava que os indivíduos seriam constrangidos a beber água fluoretada. Apesar disso, as decisões no plano científico-técnico e no plano judicial foram favoráveis à fluoretação. Pouco a pouco, a jurisprudência foi se consolidando favoravelmente à fluoretação, e os direitos individuais pareciam salvaguardados, uma vez que, segundo o princípio da proteção, caberia ao Estado limitar o exercício dos direitos individuais, objetivando o bem comum - nesse caso, a prevenção da cárie.

Posteriormente, a ênfase nos questionamentos à medida foi posta em sua segurança para a saúde humana (princípio da não-maleficência) e em sua efetividade (princípio da beneficência). Quanto a esses aspectos, Block21 afirma que os estudos que apresentavam essas objeções não foram aceitos pela comunidade científica e pela justiça, por apresentarem graves distorções metodológicas.

Com a consolidação da fluoretação como uma medida segura e efetiva na prevenção da cárie, sua expansão teve grande impulso, notadamente nos Estados Unidos e no Brasil, na segunda metade do século 20 (Narvai16). Nos Estados Unidos, pretende-se a continuidade dessa expansão, uma vez que a medida integra o conjunto de metas do documento Healthy people 2010: a meta $21-9$ fixa em $75 \%$ da população a cobertura da fluoretação naquele país em 2010, partindo de uma cobertura de 62\% em 1992 (Centers for Disease Control and Prevention 22). No Brasil, a fluoretação das águas é uma das prioridades da política nacional de saúde bucal
(Brasil14), tendo sido reivindicada nas três conferências nacionais de saúde bucal realizadas no país, em 1986, 1993 e 2004 (Narvai et al.23).

Constatou-se que a expansão da fluoretação da água foi acompanhada por um aumento na exposição aos fluoretos. Os autores referiram que tal aumento, que se seguiu ao início da fluoretação, na segunda metade do século 20, ocorreu devido ao surgimento de novos veículos para o produto, como suplementos dietéticos, dentifrícios, géis e soluções para aplicação tópica, soluções para bochechos, alimentos e bebidas industrializados processados com água fluoretada. Essa maior exposição a produtos fluorados acarretou uma redução na diferença dos níveis de cárie entre as populações habitando localidades com e sem água fluoretada. Parte substantiva dessa maior exposição se deve ao emprego do dentifrício como veículo para o flúor (Murray11, Burt24).

Esse declínio nas diferenças observadas nos níveis de cárie em populações expostas e nãoexpostas à água fluoretada pode ser explicado pela difusão dos efeitos da fluoretação entre essas localidades (efeito "halo"), decorrente da livre circulação e consumo de produtos contendo flúor, tanto em localidades com água fluoretada quanto em localidades sem água fluoretada. E, também, pela diluição dos efeitos preventivos da água fluoretada diante das novas fontes de fluoretos, com a correspondente redução do poder preventivo do método, tendo em vista a relativização do seu impacto em contextos em que não é a única medida em operação. O produto dessa maior exposição aos produtos fluorados é o aumento dos níveis de fluorose muito leve, com tendência de aumento nas frações das categorias de fluorose leve e moderada, levando pesquisadores e autoridades de saúde a tomarem providências para diminuir a exposição global aos fluoretos (Burt24, Coggon \& Cooper ${ }^{25}$ ).

Nesse contexto, a literatura consultada recomenda a manutenção da fluoretação, a adoção de medidas de vigilância epidemiológica e sanitária, controle e fiscalização dos produtos fluorados, novas pesquisas, desenvolvimento de legislação compatível, recomendações institucionais e educação da população para se minimizar o risco de fluorose.

\section{As entrevistas}

Nas entrevistas com os profissionais brasileiros, sentimentos como angústia, insegurança e indecisão foram referidos quando decisões 
precisavam ser tomadas. Tais sentimentos foram tidos como decorrentes do modo de implementação da política de uso de produtos fluorados.

Entre as principais causas desses sentimentos, citaram-se:

a) a inexistência, insuficiência ou inadequação da legislação sobre os produtos fluorados; b) as normas sobre os procedimentos coletivos de prevenção de cárie devem ser flexibilizadas;

c) não parece haver, por parte do poder público, uma postura pró-ativa para conhecer e utilizar as evidências científicas relativas à eficácia e segurança dos produtos fluorados;

d) adotam-se pressupostos de eficácia e segurança sem que as decisões sejam confirmadas por novas pesquisas, ficando os tomadores de decisão desinformados em relação aos novos conhecimentos científicos;

e) o heterocontrole dos teores de flúor na água não é realizado em todo o país, aumentando os riscos de fluorose (malefício) e a probabilidade de fracasso na prevenção da cárie em função de os teores de flúor se encontrarem, freqüentemente, abaixo do ideal;

f) falta de fóruns e instâncias de discussão que possibilitem a determinação de missões institucionais relacionadas ao uso de produtos fluorados;

g) desconhecimento das recomendações existentes na literatura, e em documentos produzidos pelo poder público, para a diminuição da exposição aos produtos fluorados;

h) a falta de normas e de fiscalização pelo poder público facilita a ação de empresas que industrializam, distribuem e vendem produtos contendo flúor - como alimentos, produtos de higiene e água engarrafada -, agravando-se o uso indiscriminado de produtos fluorados;

i) no nível local (municípios) parece não haver segurança sobre o seu grau de autonomia para realizar ações e embargar produtos, ficando na dependência de decisões das esferas superiores;

j) os levantamentos epidemiológicos de fluorose não são confiáveis, dada a dificuldade de diagnóstico das lesões;

k) os prescritores abusam na indicação dos produtos fluorados, demonstrando falta de conhecimento, de critérios científicos e de ética quanto à finalidade da prescrição;

1) é necessário alertar a população, os prescritores e os tomadores de decisão sobre o uso correto desses produtos, seus riscos e benefícios; m) apesar de existirem evidências científicas e conhecimentos suficientes para permitir que medidas cabíveis sejam tomadas na prevenção da fluorose dentária, persistem incertezas quanto ao impacto dos níveis de ingestão de fluoretos como causa de fluorose, o que acaba por retardar a necessária implantação, a curto prazo, das medidas para resolver o problema; n) insensibilidade e, em certos casos irresponsabilidade, dos dirigentes empresariais quanto aos riscos e malefícios potenciais oriundos dos produtos que fabricam, distribuem e vendem.

\section{Discussão}

Entre os entrevistados, os conflitos de ordem ética referentes ao emprego de produtos fluorados em saúde pública referem-se à autonomia e à justiça distributiva dos benefícios e danos, assim como ao risco físico representado pelo aumento da ocorrência de fluorose dentária. Dos dez entrevistados, nove fizeram menção a algum desses dilemas, sendo que dois declararam não ter se dado conta disso.

Pode-se considerar que os conflitos de ordem ética não parecem ser resolvidos, unicamente, pela existência de legislação ou de evidências científicas que possam amparar as decisões. Entretanto, legislação e evidências científicas foram considerados instrumentos fundamentais para que decisões eticamente adequadas sejam tomadas com segurança.

Não houve, entre os entrevistados, alusões à restrição da autonomia individual. Isso pode ser interpretado como decorrente do fato de que a saúde pública atua segundo o princípio da proteção, através de medidas consideradas paternalistas, nas quais a perda parcial da autonomia pode ser justificada pelo benefício - no caso, a redução da cárie. Como no contexto brasileiro a legislação sobre o assunto é federal, a falta de autonomia do município para decidir sobre produtos fluorados, especialmente a água, foi considerada inaceitável para alguns entrevistados. Mas outros consideraram aceitável essa característica da institucionalidade brasileira.

Foi visto como improvável que a população de menor poder aquisitivo, grata pela distribuição de produtos fluorados por parte do poder público, tenha autonomia e esclarecimento para questionar a qualidade e a pertinência do emprego desses produtos em programas de prevenção.

Ao contrário, a população com maior poder aquisitivo, tida como potencial questionadora 
do uso de produtos fluorados - por sua maior capacidade de consumo e acesso a produtos industrializados em geral -, poderia apresentar maior risco para fluorose. A possibilidade de futuros questionamentos por parte desses setores da população, com conseqüentes repercussões sobre o uso dos produtos fluorados, suscitou receio de vários dos entrevistados.

Quanto à justiça distributiva dos benefícios, a fluoretação da água foi considerada medida de saúde pública equânime, sendo que os demais produtos beneficiariam somente a população com maior poder aquisitivo. Predominou, na literatura e nas entrevistas, a opinião geral de que a medida deve ser mantida por sua abrangência e benefícios, além de apresentar uma relação custo-benefício muito favorável. Esta visão está em conformidade com o achado de Frias ${ }^{26}$, que constatou que a fluoretação da água apresentou um custo médio de $\mathrm{R} \$ 0,08$ (US\$ 0,03) per capita/ano na cidade de São Paulo, em 2003. O custo acumulado em 18 anos de implantação e manutenção da fluoretação na capital paulista foi de R \$1,44 (US\$ $0,94)$ per capita. A análise do benefício/custo da fluoretação, apenas para o grupo etário de 7 a 12 anos, indicou uma economia de custos da ordem de R $\$ 348,68$ (US\$ 113,95) no serviço privado e de R\$ 83,68 (US\$27,35) no serviço público, por habitante/ano.

Os entrevistados consideraram ainda que os demais produtos fluorados seriam de acesso restrito à maioria da população. $\mathrm{O}$ benefício da redução da cárie dentária, devido ao uso do flúor nas águas de abastecimento e em outros produtos, sobrepujaria amplamente os malefícios, de acordo com as opiniões predominantes na literatura e nas entrevistas.

A causa principal do dilema enfrentado para decidir sobre o uso de produtos fluorados parece consistir na dificuldade de se balancear riscos e benefícios. E recaiu, essencialmente, sobre o emprego da água de abastecimento público como veículo. Apenas secundariamente o dentifrício, e os demais produtos contendo flúor, foram mencionados.
Constatou-se que tal dilema tem sido resolvido, na maioria das vezes, admitindo-se que haveria justiça no emprego desses produtos e que seu benefício, no contexto brasileiro, ainda seria maior que o malefício. Alguns entrevistados reconheceram, entretanto, que há violação do princípio da autonomia.

Isto está de acordo com a afirmação de Cohen \& Locker 15 quando, abordando especificamente aspectos éticos do uso de água fluorada no contexto canadense, e assinalando que há risco no emprego dessa medida, mencionam que aparentemente não há saída desse conflito de valores, que permaneceria mesmo que a fluoretação envolvesse benefício sem riscos.

Assim, não tendo aparentemente solução no plano ético, as decisões sobre o emprego de produtos fluorados em saúde pública, inclusive as relativas à fluoretação de águas de abastecimento público e dentifrícios, têm de ser tomadas no plano político. Neste plano, por definição, qualquer decisão atende a certos interesses e contraria outros. Decidir que interesses devem ser contrariados em cada contexto coloca em relevo a importância dos valores democráticos e as relações entre saúde e democracia. Em relação à fluoretação das águas de abastecimento público, o Parlamento brasileiro tomou importante decisão em 2004: analisou e rejeitou um projeto de lei que pretendia interromper a fluoretação das águas no país (Narvai et al.23).

Decisões políticas dessa natureza não resolvem, por certo, conflitos éticos.

Mas não há dúvida de que resoluções desse tipo contribuem para ampliar os fundamentos sobre os quais os tomadores de decisão em saúde têm de agir. Portanto, é de se esperar que, com base nessa decisão do Legislativo, haja uma diminuição da ocorrência de alguns dos sentimentos mencionados nas entrevistas - tais como angústia, insegurança e indecisão -, relacionados ao emprego da água e de outros produtos como veículo para fluoretos, com vistas à prevenção da cárie.

\section{Colaboradores}

Kalamatianos PA e Narvai PC participaram igualmente em todas as etapas da elaboração do artigo. 


\section{Referências}

1. Garrafa V. Bioética, saúde e cidadania. O Mundo da Saúde 1999; 23(5):263-69.

2. Schramm FR, Kottow M. Principios bioéticos en salud pública: limitaciones y propuestas. Cad Saúde Pública 2001; 17(4):1-11.

3. Goldim JR. Dilema [artigo na internet sem periódico]. 2002 [acessado 2002 jul 2]. Disponível em: http:// www.ufrgs.br/HCPA/gppg/dilema.htm

4. Fortes PAC. Ética e saúde: questões éticas, deontológicas e legais. Tomadas de decisões. Autonomia e direitos do paciente. Estudos de casos. São Paulo: EPU; 1998.

5. Kass NE. An ethics framework for public health. Am J Public Health 2001; 91(11):1776-82.

6. Frazão P. Tecnologias em saúde bucal coletiva. In: Botazzo C, Freitas SFT, coordenadores. Ciências sociais e saúde bucal: questões e perspectivas. São Paulo: Unesp, Edusc; 1998. p. 159-74.

7. Schramm FR, Escotesguy CC. Bioética e avaliação tecnológica em saúde. Cad Saúde Pública 2000; 16(4): 951-61.

8. Fortes PAC. Bioética e saúde pública: tópicos de reflexão para a próxima década. O Mundo da Saúde 2000; 6(1):31-8.

9. Kalamatianos PA, Narvai PC. Uma proposta de esquema para a análise ética das ações de saúde pública. O Mundo da Saúde 2004; 28(1):34-41.

10. Fejerskov O, Mangi F, Bauelum V, Moller IJ. Fluorose dentária: um manual para profissionais da saúde. São Paulo: Editora Santos; 1994.

11. Murray JJ. O uso correto de fluoretos em saúde pública. Genebra: OMS; São Paulo: Editora Santos; 1992.

12. McDonagh MS, Whiting PF, Wilson PM, Sutton AJ, Chestnutt I, Cooper J, et al. Systematic review of water fluoridation. BMJ 2000; 321:855-9.

13. Horowitz HS. The effectiveness of community water fluoridation in the United States. J Public Health Dent 1996; 56(5 Sp No):253-8. [Presented at the International Symposium Celebrating the 50th Anniversary of Water Fluoridation; 1995 Sept; Grand Rapids (Michigan)].

14. Brasil. Ministério da Saúde. Área Técnica de Saúde Bucal. Fluoretação da água de consumo público no Brasil. 1999 [acessado 2002 dez 10]. Disponível em: http:// www.saude.gov.br/programas/bucal/inicial.html
15. Cohen H, Locker D. The science and ethics of water fluoridation. J Can Dent Assoc 2001; 67 (10):578-80.

16. Narvai PC. Cárie dentária e flúor: uma relação do século XX. Rev C S Col 2000; 5(2):381-92.

17. Brasil. Ministério da Saúde. Secretaria de Atenção à Saúde. Departamento de Atenção Básica. Coordenação Nacional de Saúde Bucal. Projeto SB Brasil 2003. Condições de saúde bucal da população brasileira 20022003: resultados principais. Brasília: MS/CNSB; 2004.

18. World Health Organization. Oral health surveys: basic methods. $4^{\text {th }}$ ed. Geneva: WHO; 1997.

19. Minayo MCS. O desafio do conhecimento: pesquisa qualitativa em saúde. 7a ed. São Paulo: Hucitec; Rio de Janeiro: Abrasco; 2000.

20. Lefèvre F, Lefèvre AMC, Teixeira JJV, organizadores. O discurso do sujeito coletivo: uma nova abordagem metodológica em pesquisa qualitativa. Caxias do Sul: Educs; 2000.

21. Block LE. Antifluoridationists persist: the constitutional basis for fluoridation. J Public Health Dent 1986; 46(4):188-98.

22. Centers for Disease Control and Prevention. Health Resources and Services Administration. Healthy people 2010: objectives for improving health - oral health. Atlanta: CDC; 2000.

23. Narvai PC, Frazão P, Fernandez RAC. Fluoretação da água e democracia. Saneas 2004; 2(18):29-33.

24. Burt BA. Fluoride: how much of a good thing? Introduction to the Symposium. J Public Health Dent 1995; 55(1):37-8 [Presented at the Annual Meeting of the AAPHD; 1994 Oct; New Orleans (LA)].

25. Coggon D, Cooper C. Fluoridation of water supplies: debate on the ethics must be informed by sound science [editorial]. BMJ 1999; 319:269-70.

26. Frias AC. Custo-efetividade da fluoretação das águas de abastecimento público no município de São Paulo, no período de 1985-2003 [tese]. São Paulo: Faculdade de Saúde Pública da Universidade de São Paulo; 2004.

Artigo apresentado em 31/03/05

Aprovado em16/08/2005

Versão final apresentada em 14/10//2005 